\title{
PET motion correction using MR-derived motion parameters
}

\author{
Matthew Bickell ${ }^{1 *}$, Thomas Koesters ${ }^{2,3}$, Fernando Boada ${ }^{2,3}$, Johan Nuyts ${ }^{1}$ \\ From PSMR14: 3rd Conference in PET/MR and SPECT/MR \\ Kos Island, Greece. 19-21 May 2014
}

${ }^{1}$ Medical Imaging Research Center, Department of Nuclear Medicine, KU Leuven, Belgium
With the improving resolution of modern PET scanners, any slight motion during the scan can cause significant blurring and loss of resolution. MRI scanners have the capacity to perform quick successive scans and thus provide a means to track motion during a scan. Hence, with the advent of simultaneous PET-MR scanners, it has become possible to use the MR scanner to track the motion and thereby provide the necessary motion parameters to correct the PET data. Using a suitable segmentation approach a separate MR scan can provide the attenuation map to produce quantitative PET images.

An FDG brain scan was acquired on a Siemens Biograph mMR PET-MR scanner. The MR scan was acquired using the Golden Angle Radial Sparse Parallel (GRASP) sequence [1], simultaneously with a 5 minute PET scan, while the patient was asked to move his head repetitively from side to side for proof-of-principle purposes. A separate static scan was also acquired prior to the motion scan, to be used as a control. The MR data were divided into a series of 268 images with a frequency of approximately $1 \mathrm{~Hz}$. The motion parameters were derived by performing a rigid ( 6 degrees-of-freedom) registration of the masked MR images to a chosen reference image. The PET list-mode data were corrected on an event-by-event basis [2,3]. List-mode maximum likelihood expectation-maximisation (accelerated with ordered subsets [4]) was used for the reconstruction, incorporating the attenuation correction (as a pre-correction to the data) as well as weighted-average sensitivity [2] to achieve a quantitative reconstruction.

Motion correction successfully removed almost all motion artefacts, recovered the resolution and allowed for quantitative images to be produced. Techniques to improve upon the coarse sampling of the MR images, such as interpolating between motion data points, will be investigated.

\section{Authors' details}

${ }^{1}$ Medical Imaging Research Center, Department of Nuclear Medicine, KU Leuven, Belgium. ${ }^{2}$ Center for Advanced Imaging Innovation and Research, New York University, USA. ${ }^{3}$ Bernard \& Irene Schwartz Center for Biomedical Imaging, Department of Radiology, NYU School of Medicine, New York, New York, USA.

Published: 29 July 2014

References

1. Feng L, Grimm R, Tobias Block K, Chandarana H, Kim S, Xu J, Axel L, Sodickson DK, Otazo R: Golden-angle radial sparse parallel MRI: Combination of compressed sensing, parallel imaging, and golden-angle radial sampling for fast and flexible dynamic volumetric MRI. Magn. Reson. Med. 2013, 00.

\section{SpringerOpen ${ }^{\odot}$}

(C) 2014 Bickell et al; licensee Springer This is an Open Access article distributed under the terms of the Creative Commons Attribution License (http://creativecommons.org/licenses/by/4.0), which permits unrestricted use, distribution, and reproduction in any medium, provided the original work is properly cited. 
2. Rahmim A, Bloomfield P, Houle S, Lenox M, Michel C, Buckley KR, Ruth TJ, Sossi V: Motion Compensation in Histogram-Mode and List-Mode EM Reconstructions: Beyond the Event-Driven Approach. IEEE Trans. Nucl. Sci. 2004, 51(5):2588-2596.

3. Kyme AZ, Zhou WW, Meikle SR, Baldock C, Fulton RR: Optimised motion tracking for positron emission tomography studies of brain function in awake rats. PLoS One 2011, 6(7):e21727.

4. Hudson HM, Larkin RS: Accelerated image reconstruction using ordered subsets of projection data. IEEE Trans. Med. Imaging 1994, 13:601-609.

doi:10.1186/2197-7364-1-S1-A53

Cite this article as: Bickell et al:: PET motion correction using MR-derived motion parameters. EJNMMI Physics 2014 1(Suppl 1):A53.

\section{Submit your manuscript to a SpringerOpen ${ }^{\circ}$} journal and benefit from:

$\rightarrow$ Convenient online submission

- Rigorous peer review

- Immediate publication on acceptance

- Open access: articles freely available online

- High visibility within the field

- Retaining the copyright to your article

Submit your next manuscript at $\boldsymbol{s p r i n g e r o p e n . c o m ~}$ 